\title{
Hybrid Processing Combining Electrostatic Levitation and Laser Heating: Application to Terrestrial Analogues of Asteroid Materials
}

\author{
Paul-François Paradis, ${ }^{1}$ Takehiko Ishikawa, ${ }^{1}$ Yuki Watanabe, ${ }^{2}$ and Junpei Okada ${ }^{1}$ \\ ${ }^{1}$ Japan Aerospace Exploration Agency, Institute for Space and Astronautical Science, ISS Science Project Office, 2-1-1 Sengen, \\ Tsukuba, Ibaraki 305-8505, Japan \\ ${ }^{2}$ Advanced Engineering Services, 1-6-1 Takezono, Tsukuba, Ibaraki 305-0032, Japan
}

Correspondence should be addressed to Paul-François Paradis, paradis.paul@jaxa.jp

Received 14 February 2011; Accepted 16 May 2011

Academic Editor: Dieter Schuöcker

Copyright ( $) 2011$ Paul-François Paradis et al. This is an open access article distributed under the Creative Commons Attribution License, which permits unrestricted use, distribution, and reproduction in any medium, provided the original work is properly cited.

Electrostatic levitation combined with laser heating is becoming a mature technique that has been used for several fundamental and applied studies in fluid and materials sciences (synthesis, property determination, solidification studies, atomic dynamic studies, etc.). This is attributable to the numerous processing conditions (containerless, wide heating temperature range, cooling rates, atmospheric compositions, etc.) that levitation and radiative heating offer, as well as to the variety of diagnostics tools that can be used. In this paper, we describe the facility, highlighting the combined advantages of electrostatic levitation and laser processing. The various capabilities of the facility are discussed and are exemplified with the measurements of the density of selected ironnickel alloys taken over the liquid phase.

\section{Introduction}

Noncontact processing of materials is required when dealing with corrosive materials or when there is a need to reach and maintain samples at high temperatures for times long enough to complete the processing. This is a stringent requirement for materials (e.g., refractory metals and ceramics) with melting temperatures higher than those of crucibles. In particular, containerless conditions are desirable to allow a host of investigations (thermophysical property measurements, high energy beam interaction (neutron, synchrotron, etc.)), solidification studies, synthesizing new phases, to name but a few. Moreover, processing without containers avoids any physical contact which can contaminate or change the shape of a sample. By doing so, data analysis is also simplified and it is possible to obtain properties of a material in its purest form. In addition, this allows to reach and maintain a material under undercooled conditions (below melting temperature). This limits heteregeneous nucleation and eases vitrification. Similarly, the reduced gravity conditions prevailing on orbiting platform (space shuttle, International Space Station, etc.), in sounding rockets, in airborne laboratory or in drop shaft, all require some sort of positioning system to maintain a processed material subject to residual forces in a specific location [16].

Electrostatic levitation is very well suited to meet the above requirements for the noncontact processing of materials. In particular, the method does not intrinsically heat the samples and does not deform them. Furthermore, it allows the processing of conducting and nonconducting materials, solid or liquid, while offering a wide field of view of the processed materials. It can operate under high vacuum or atmospheric pressure, it can control the rotation of samples, and can be equipped so that controlled induced oscillation and nucleation are possible in a processed material.

Most of the studies in materials science do require some sort of heating. In the context of contactless processing, radiative heating, in particular, laser heating, is very attractive because it allows precisely controlled and fast heating 
and cooling. Moreover, the laser can impart momentum to a processed material through photon momentum transfer. By selecting the emission wavelength, the laser source allows to target specific materials and also permits to avoid spectral interference (e.g., with cameras, pyrometer).

Using laser heating with an electrostatic levitator combines their own merits with the additional advantages of having a processing facility in which heating and levitation controls are independent. Furthermore, fast heating and fast radiative cooling are possible when the materials are processed under high vacuum. In addition, the laser beam can access specific region of a levitated sample, perform localized heating, generate micrograving (e.g., spherical IC), or photo-induce interactions (physical, chemical, etc.). In such a hybrid facility, the field of view of the sample is not blocked by a heating device such as coils.

In this paper, we first describe a hybrid processing facility that combines electrostatic levitation and laser heating, highlighting its capability in terms of environment, heating, and cooling. The fabrication as well as the processing of a man-made analogue of asteroid materials is presented. Representative density data for a few iron-nickel alloys are then reported. These data could be of help for numerical modeling and simulation of early formation, differentiation, and disruption of asteroids.

\section{Experimental Methods and Procedures}

2.1. Electrostatic Levitation. The measurements reported in this paper have been carried out using an electrostatic levitation furnace developed by JAXA $[7,8]$. The apparatus described here was based on a design by Rhim et al. [2] but modified in areas of sample handling, charging, electrode design and configuration, feedback implementation, levitation initiation, imaging, and heating configuration [711] without which the described experiments would have been difficult to perform. Figure 1 illustrates schematically the electrostatic levitation furnace. The facility consisted of a stainless steel chamber which was typically evacuated to $\sim 10^{-5} \mathrm{~Pa}$ before sample processing was initiated. A similar facility can sustain a pressurized atmosphere of up to $1 \mathrm{MPa}$ with a variety of pure or mixture of gases (air, $\mathrm{N}_{2}, \mathrm{O}_{2}, \mathrm{Kr}$, etc.).

In this work, Fe-Ni binary alloy samples were prepared by arc melting measured quantities of solid pieces of the component metal in a water-cooled copper hearth under Ar atmosphere. The metals used for the alloy preparation were high purity iron (99.995\% mass) and nickel (99.99\% mass) from Nilaco, Tokyo, Japan. Once a large piece of material was made, it was cut into small pieces that were arc melted once again into ca. $2 \mathrm{~mm}$ diameter spheroid samples. For this study, the emphasis was given on alloys with three compositions, $\mathrm{Fe}_{50} \mathrm{Ni}_{50}, \mathrm{Fe}_{75} \mathrm{Ni}_{25}$, and $\mathrm{Fe}_{25} \mathrm{Ni}_{75}$ because M-class asteroids (Tholen taxonomic scheme) $[12,13]$ and part of classes Q and S asteroids [14] are believed to be constituted of such metallic alloys. Analysis of iron meteorites originating from the $\mathrm{M}$-class asteroids revealed composition of taenite $\left(\mathrm{Fe}_{80-35} \mathrm{Ni}_{20-65}\right)$ or of kamacite $\left(\mathrm{Fe}_{95-90} \mathrm{Ni}_{5-10}\right)$ [15]. Data of thermophysical properties of $\mathrm{Fe}-\mathrm{Ni}$ alloys would provide valuable information for numerical modeling of asteroid impact, formation, and evolution (e.g., melting, differentiation) [16]. Therefore, this would help to understand the primeval processes in the asteroid belt and give insights about the formation of the solar system. Moreover, the data could be of interest to elucidate issues related to the core of the Earth.

To handle the samples, a sliding cartridge containing ten individual tungsten pedestals was used. This helped to circumvent any cross-talk contamination problems between distinct samples and permitted the handling of soft, porous, or submillimeter materials $[7,8]$. To perform a processing experiment, one of the 10 samples located in the cartridge was brought up to the level of a bottom electrode. The sample was then charged by thermionic emission and was levitated between two horizontal electrodes, a concave bottom electrode $(30 \mathrm{~mm}$ dia.), and a flat top electrode (10 mm dia.), both having a through hole. An electrical field of $\sim 12 \mathrm{kV}$ field was applied between the two electrodes, and a feedback control software was activated. The top electrode was gimbaled with three micrometer screws, allowing accurate electrode balancing and spacing $(10 \mathrm{~mm}$ between both electrodes). These electrodes were mainly effective for vertical position sample control. However, the conical electrical field distribution of the electrode configuration provided a restoring force towards the center, thus contributing to the horizontal position control as well. In addition, four secondary spherical electrodes with applied positive or negative potentials, distributed around and at the height of the levitated sample, were used to further control the horizontal position. Since the electrostatic scheme could not produce a potential minimum, a feedback position control system was necessary. Position sensing was achieved with a set of orthogonally disposed He-Ne lasers and the associated position detectors. The position information, obtained by the shadow of the He-Ne laser illuminated sample, was fed to a computer that input, new values of $x, y$, and $z$ to a high voltage amplifier at a rate of $720 \mathrm{~Hz}$ so that a prefixed position could be maintained. The lower electrode was also surrounded by four coils that were used as a stator to generate a horizontal and rotating magnetic field. The magnetic field was used for sample rotation control [17]. In addition, an ac voltage could be superimposed on the levitation voltage from the top electrode to excite drop oscillations for the surface tension and viscosity experiments.

The sample was observed by three charged-coupleddevice (CCD) cameras (Figure 1). One camera offered a general view of both the electrode assembly and the sample. Two high resolution CCD cameras, equipped with telephoto objectives in conjunction with high intensity UV or visible background lights allowed sample perimeter and surface features to be analyzed [9]. In addition to the CCD cameras, each telephoto objective was equipped with a half-mirror, an interference filter ( $\mathrm{He}-\mathrm{Ne}$ emission line), and a detector. One of the detectors, coupled with a monochromator slit, was used to determine the oscillating drop amplitude from the shadow of an He-Ne laser backlit sample and was dedicated to the measurement of the sample oscillation [18]. The other sensor was used for sample rotation rate measurement by 


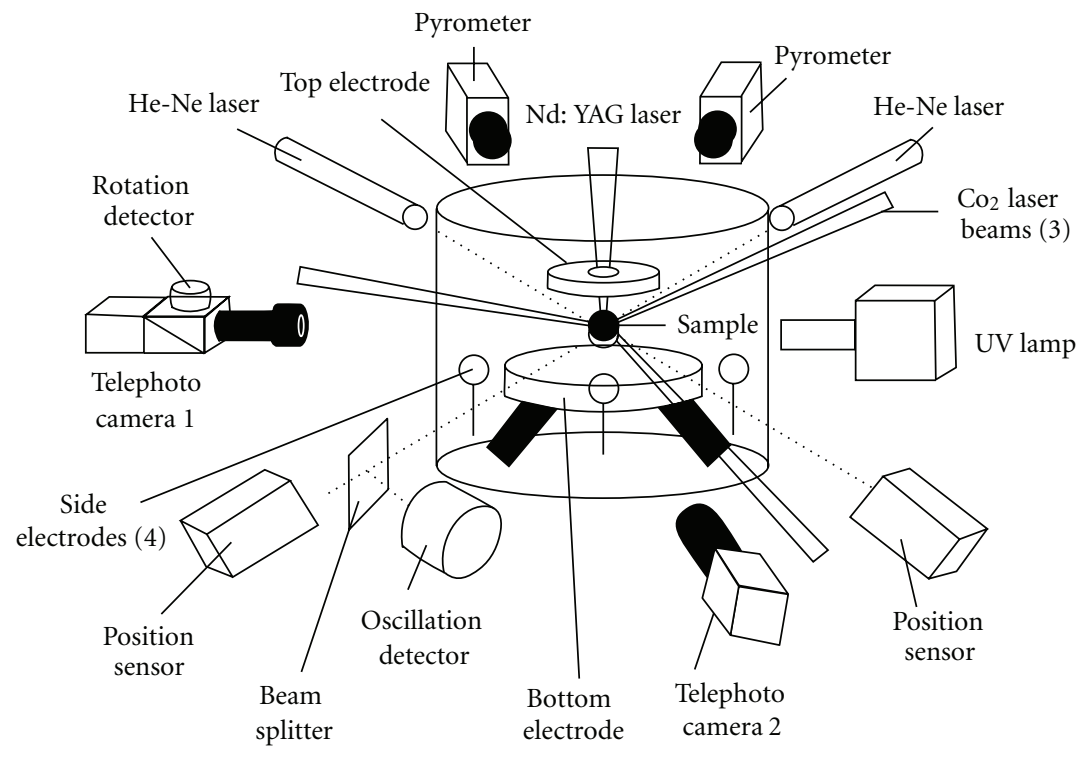

FIGURE 1: Schematic representation of the electrostatic levitator.

detecting the reflected He-Ne laser beam from its surface [17].

Once the sample was levitated, the next step in the experiments consisted in melting and resolidifying a levitated sample to confirm pyrometer calibration and alignment. The sphericity of the sample was confirmed by software analysis by comparing its shape with that of a calibration sphere.

2.2. Laser Processing. Sample heating was performed using the radiation coming from computer controlled $\mathrm{CO}_{2}$ and Nd:YAG lasers (Figure 1). To avoid the destabilizing effect of photon and evaporative anisotropic-induced forces [19] and to maintain good position stability, for materials processed under vacuum, while observing the constraint of the chamber layout, a flattened tetrahedral laser heating configuration was implemented (Figure 2) $[10,11]$. Specifically, three focused beams ( $50 \mathrm{~W}$ each) of $\mathrm{CO}_{2}$ lasers (Synrad, $10.6 \mu \mathrm{m}$ emission) in a same plane, separated by 120 degrees, hit the specimen. In addition, the focused beam of a $500 \mathrm{~W}$ Nd:YAG laser (Lee Laser, $1.064 \mu \mathrm{m}$ emission) (equipped with a $0-90 \%$ power attenuator) coming from the top can be used when additional power is needed (e.g., for refractory materials such as Os, Re, and W). Heating with the most powerful laser along the vertical was the best configuration as the strongest field and the fastest feedback were also along this axis. Besides the exceptional 3D sample position stability it provided, this multibeam heating configuration helped to control sample rotation and improved temperature homogeneity.

2.3. Density Measurements. In this paper, one of the capabilities of the facility is exemplified with the measurements of the density of selected iron-nickel alloys. The density was determined by simultaneously recording the temperature and magnified images of a spherical sample illuminated from behind with an ultraviolet source [9]. Upon closing the shutters of all lasers, the sample cooled and even undercooled, yielding data over a large temperature range.
The sample area was extracted from each digitized video images and matched to a temperature profile. These images were calibrated by levitating a sphere of precisely known diameter under identical conditions. Since the sample was axi-symmetric and because its mass was known, the density could be found for each temperature by dividing the mass by the volume.

2.4. Other Processing Capabilities. Several capabilities of combining electrostatic levitation and laser heating are briefly described. The interested reader can consult the given references for more information.

2.4.1. Surface Tension and Viscosity Measurements. In addition to its usefulness for industrial processes (e.g., bubble migration, refining, casting, welding), the knowledge of the surface tension and viscosity and their temperature dependences is important in fundamental studies (e.g., atomic dynamics, surface physics) and when designing new high performance alloys [20]. The surface tension and the viscosity can be determined with the current facility by studying the behavior of the sample oscillation about its equilibrium shape [21]. In this technique [18, 22], an oscillation is induced to the levitated sample by superimposing a small sinusoidal electric field on the levitation field. The transient signal that followed the termination of the excitation field is detected and analyzed. This is done several times at a given temperature and repeated on a large temperature range. The surface tension can then be found using the characteristic oscillation frequency of the signal after correcting for nonuniform surface charge distribution $[23,24]$. Similarly, the viscosity is obtained using the decay time of the same signal [24].

2.4.2. Vapor Pressure Measurements. The sample area variation in time could be accurately measured for a given temperature using the UV imaging technique, knowing 


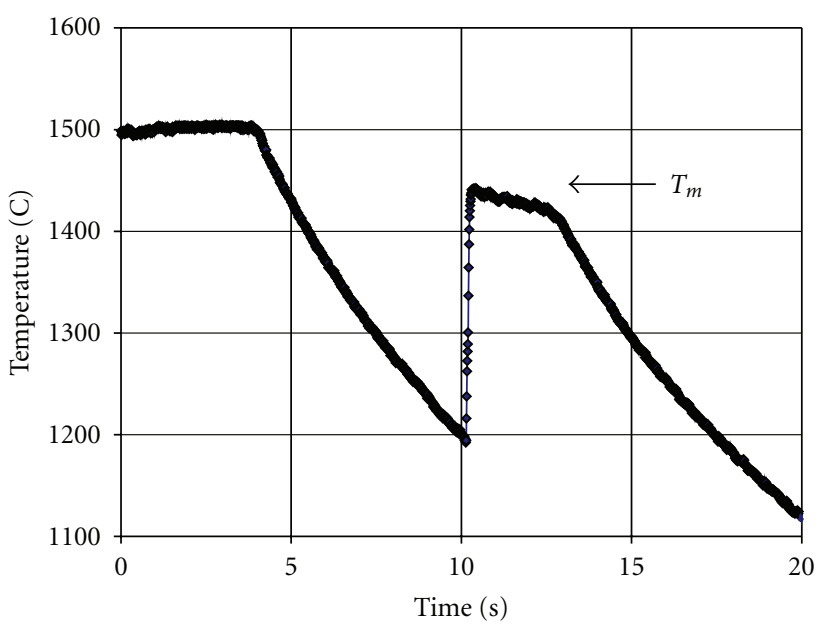

(a)

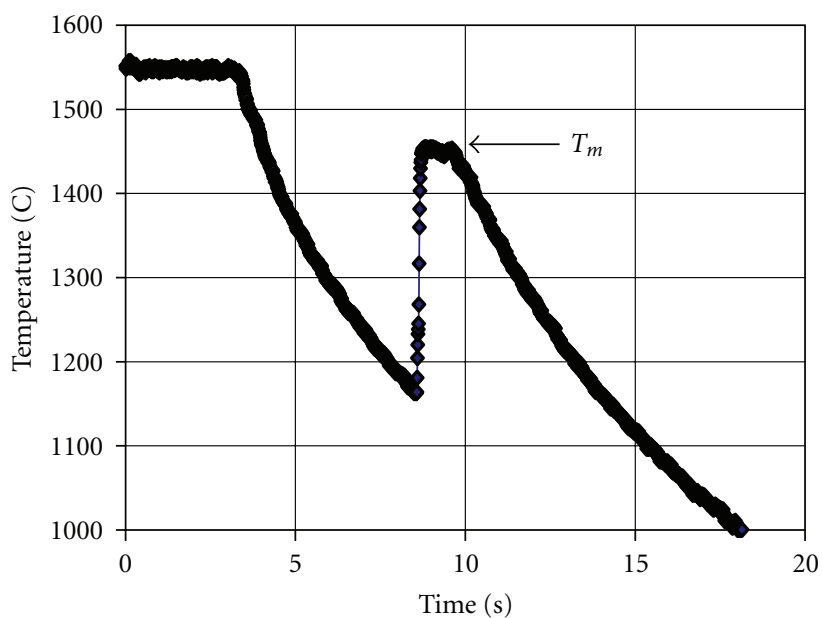

(b)

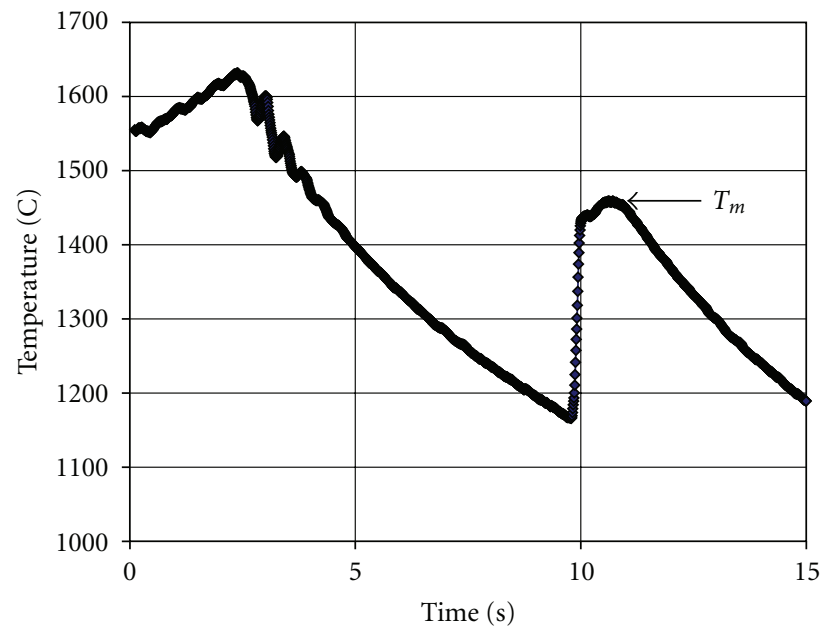

(c)

Figure 2: Temperature history profile for electrostatically levitated Fe-Ni alloy samples (a) $\mathrm{Fe}_{25} \mathrm{Ni}_{75}$, (b) $\mathrm{Fe}_{50} \mathrm{Ni}_{50}$, and (c) $\mathrm{Fe}_{75} \mathrm{Ni}_{25}$. For example in (b), a $2.7 \mathrm{~mm}$ diameter sample $\left(18.42 \mathrm{mg}\right.$ ) was heated up to $1550^{\circ} \mathrm{C}$. At time $\sim 10 \mathrm{~s}$, the laser power was deliberately turned off, the sample cooled down to the undercooled phase, and then solidified as evidenced by recalescence (release of the latent heat of fusion).

TABle 1: Comparison of density data measured in this study and that reported in the literature. Note that the data were compared for identical temperatures.

\begin{tabular}{|c|c|c|c|c|c|c|c|}
\hline & $\begin{array}{r}\mathrm{Fe}_{75} \mathrm{Ni}_{25} \\
\left(\mathrm{~kg} / \mathrm{m}^{3}\right)\end{array}$ & $\begin{array}{c}\text { Difference } \\
(\%)\end{array}$ & $\begin{array}{c}\mathrm{Fe}_{50} \mathrm{Ni}_{50} \\
\left(\mathrm{~kg} / \mathrm{m}^{3}\right)\end{array}$ & $\begin{array}{c}\text { Difference } \\
(\%)\end{array}$ & $\begin{array}{c}\mathrm{Fe}_{25} \mathrm{Ni}_{75} \\
\left(\mathrm{~kg} / \mathrm{m}^{3}\right)\end{array}$ & $\begin{array}{c}\text { Difference } \\
(\%)\end{array}$ & Technique \\
\hline This study $\left(1550^{\circ} \mathrm{C}\right)$ & 7170 & - & 7300 & - & 7540 & - & Levitation \\
\hline This study $\left(1540^{\circ} \mathrm{C}\right)$ & 7180 & - & 7310 & 一 & 7550 & - & Levitation \\
\hline Benedicks et al. $\left(1550^{\circ} \mathrm{C}\right)[25]$ & 7220 & -0.60 & 7360 & -0.89 & 7500 & 0.51 & Manometer \\
\hline Dzhemilev et al. $\left(1550^{\circ} \mathrm{C}\right)[26]$ & 7270 & -1.34 & 7430 & -1.73 & 7560 & -0.33 & Sessile drop \\
\hline El-Chansan et al. $\left(1540^{\circ} \mathrm{C}\right)$ [27] & 7200 & -0.33 & 7360 & -0.81 & 7520 & 0.36 & Expansion \\
\hline Popel et al. $\left(1550^{\circ} \mathrm{C}\right)[28]$ & 7190 & -0.21 & 7360 & -0.79 & 7510 & 0.34 & Sessile drop \\
\hline Sharan et al. $\left(1550^{\circ} \mathrm{C}\right)[29]$ & 7240 & -0.96 & 7410 & -1.55 & 7570 & -0.39 & Sessile drop \\
\hline Watanabe et al. $\left(1550^{\circ} \mathrm{C}\right)[30]$ & 7210 & -0.46 & 7400 & -1.38 & 7580 & -0.53 & $\begin{array}{c}\text { Maximum bubble } \\
\text { pressure }\end{array}$ \\
\hline
\end{tabular}




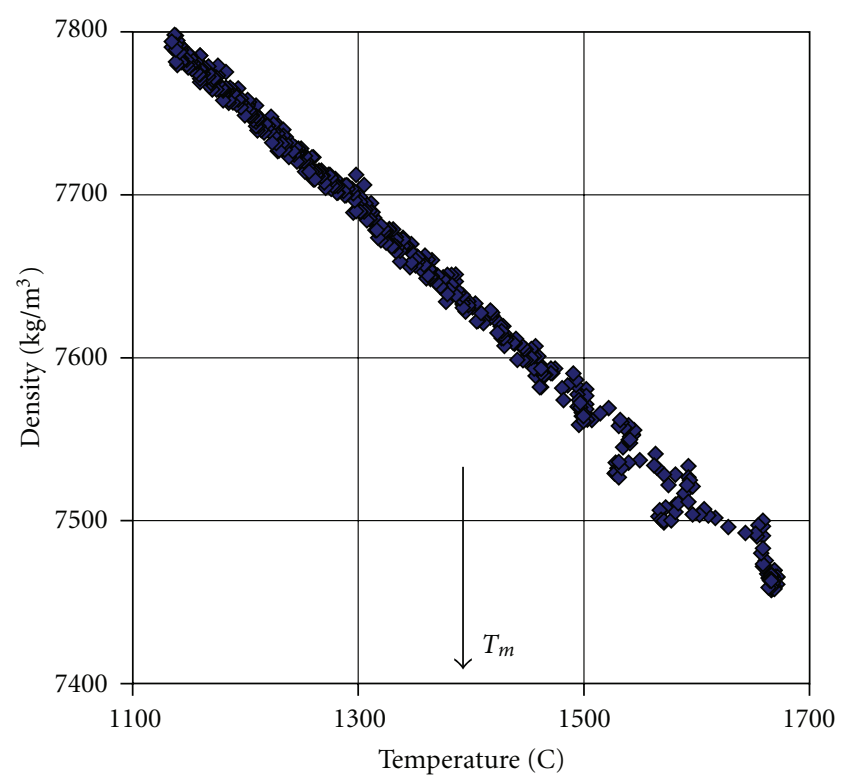

(a)

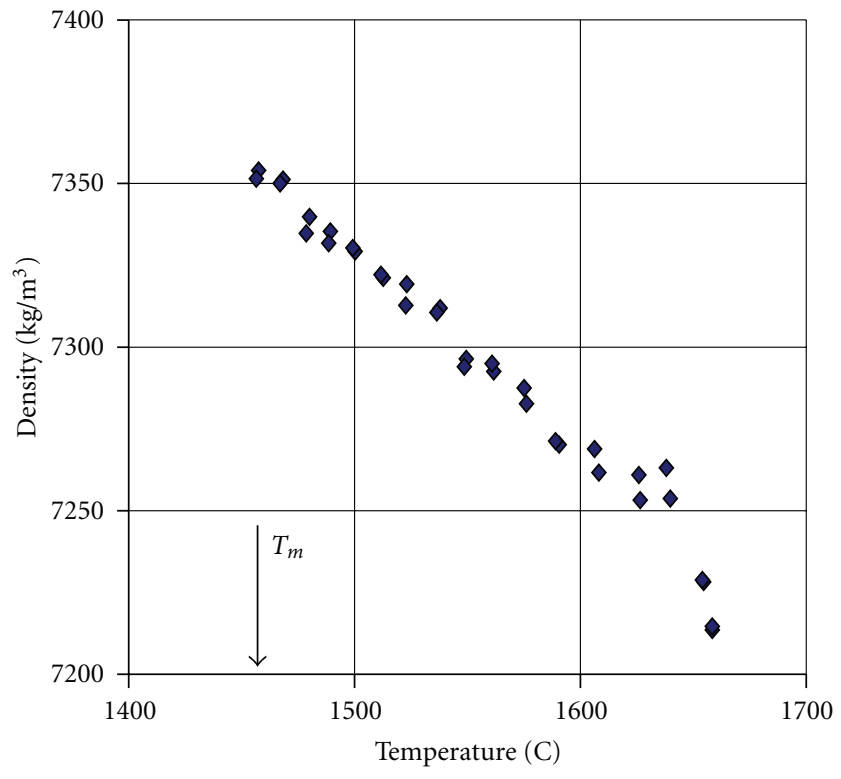

(b)

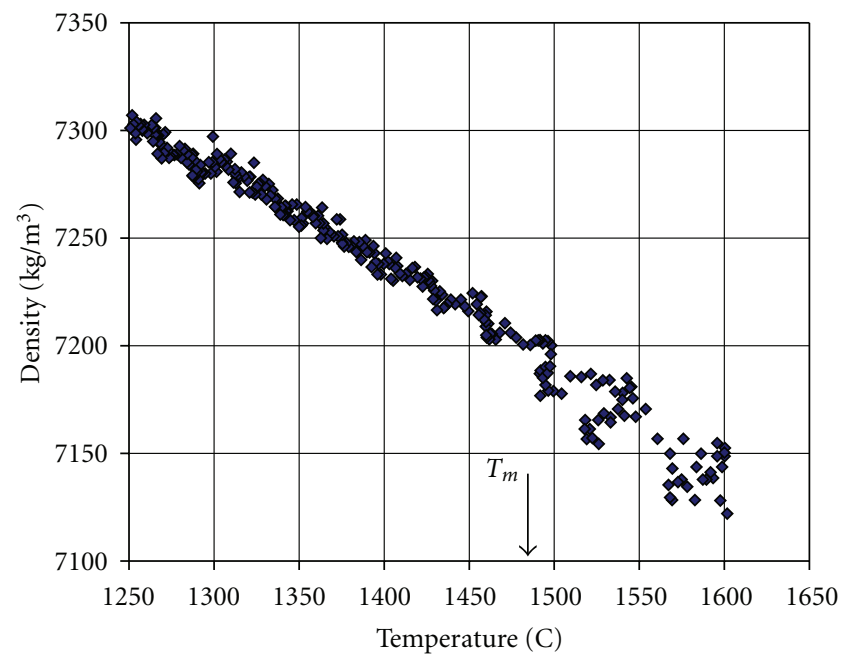

(c)

Figure 3: Density of liquid Fe-Ni alloys versus temperature: (a) $\mathrm{Fe}_{25} \mathrm{Ni}_{75}$, (b) $\mathrm{Fe}_{50} \mathrm{Ni}_{50}$, and (c) $\mathrm{Fe}_{75} \mathrm{Ni}_{25}$. For all graphs, the region below $\sim 1450^{\circ} \mathrm{C}$ corresponds to the undercooled state of the alloy.

the elapsed time between the start and the end of an experiment. Since the sample evaporated isotropically, the effusion Knudsen method [31] could be utilized assuming that the effective area of effusion was the surface of the sample at a given time. Therefore, the vapor pressure could be found using the measured rate of evaporation in vacuo, the gas constant, the sample temperature, and the molecular weight of the material [32].

2.4.3. Atomic Structure Characterization by Neutron Scattering Experiments. Vacuum electrostatic levitation furnace was also developed for the structural study of materials above the melting point as well as in undercooled phase by neutron scattering $[33,34]$ and synchrotron radiation [35].
Preliminary experiments performed with a solid alumina sample did not reveal any sharp peaks in the background data coming from the furnace materials which is an advantage compared to other methods [36-38]. The observed diffraction peak intensities and location were identified as those derived from the mirror indices of hexagonal structure of alumina and were in complete agreement with those reported in the literature [39]. Experiments to investigate the characterization of the atomic structure and dynamic of liquid boron by synchrotron radiation have also been initiated [35].

2.4.4. Processing and Solidification from Supercooled Phase. Besides elemental metals, several oxides (e.g., $\mathrm{Nd}-\mathrm{CaAl}_{2} \mathrm{O}_{4}$, 
$\mathrm{Y}_{3} \mathrm{Al}_{5} \mathrm{O}_{12}, \mathrm{Al}_{2} \mathrm{O}_{3}$, some slags, $\mathrm{BiFeO}_{3}, \mathrm{BaTiO}_{3}$ ) have been processed using either the pressurized or vacuum facilities. It was even possible to vitrify several compositions from the undercooled state $[40,41]$. The containerless solidification behavior of $\mathrm{Nd}_{2} \mathrm{Fe}_{14} \mathrm{~B}$ was also studied at different cooling rates and the effects of undercooling depth on the microstructure and magnetization were investigated [42]. For the sample solidified from the deepest undercooling level, a fine microstructure was obtained and the higher magnetization was revealed. Solidification of barium titanate $\left(\mathrm{BaTiO}_{3}\right)$ from deep undercooled phases revealed transparent materials that consisted of micrometer-size particles and a single crystal phase exhibiting a giant dielectric constant and weak temperature dependence [43].

\section{Results}

3.1. Heating and Cooling. Here we report representative data obtained with the combined capabilities of electrostatic levitation and laser heating.

The radiance temperature was measured by two singlecolor automatic pyrometers (Chino Corp, Model IR-CS 2S CG and Chino Corp, Model IR-AP: $0.96 \mu \mathrm{m}$ and $0.98 \mu \mathrm{m}$ working wavelength, $10 \mathrm{~Hz}$ and $120 \mathrm{~Hz}$ acquisition rates, $\pm 50 \mathrm{~K})$ and was calibrated using the known melting temperature of the binary alloys. Calibration to the true temperature was performed from Planck's law after adjusting the melting plateau to correspond to the known melting point of each binary alloy $\left(\mathrm{Fe}_{50} \mathrm{Ni}_{50}, 1450^{\circ} \mathrm{C}, \mathrm{Fe}_{75} \mathrm{Ni}_{25}, 1475^{\circ} \mathrm{C}\right.$, and $\mathrm{Fe}_{25} \mathrm{Ni}_{75}, 1460^{\circ} \mathrm{C}$ ) [44]. The thermal history for three compositions: $\mathrm{Fe}_{25} \mathrm{Ni}_{75}, \mathrm{Fe}_{50} \mathrm{Ni}_{50}$, and $\mathrm{Fe}_{75} \mathrm{Ni}_{25}$ is illustrated in Figure 2. Typical profiles for cooling samples of three alloy compositions exhibiting undercooling (from 260 degrees for $\mathrm{Fe}_{25} \mathrm{Ni}_{75}$ to 310 degrees for $\mathrm{Fe}_{75} \mathrm{Ni}_{25}$ ) and recalescence (sudden temperature rise due to the release of the latent heat of fusion of undercooled samples upon solidification) are shown in Figure 2. For example, in Figure 2(b), a $2.7 \mathrm{~mm}$ diameter sample $(18.42 \mathrm{mg})$ was heated up to $1550^{\circ} \mathrm{C}$. At time $\sim 10 \mathrm{~s}$, the laser power was deliberately turned off and the sample cooled down to the undercooled phase before solidifying as evidenced by recalescence.

Although recent measurements with a fast polarimeter showed variations in the emissivity in the liquid phase for several metals [44], the lack of data for the undercooled binary alloys prompted us to assume that the emissivity remained constant over the whole undercooled range. Optical microscopy and electron probe microanalysis were performed to ensure that voids or oxide or nitride layers were not present on the surface or in the bulk of the solidified samples and that the materials did not undergo incongruent evaporation during processing.

3.2. Density Measurements. The density measurements of liquid binary alloys were taken over a large temperature range, covering the undercooled region by a few hundred degrees. The density data are presented in Figure 3 for three compositions: $\mathrm{Fe}_{25} \mathrm{Ni}_{75}, \mathrm{Fe}_{50} \mathrm{Ni}_{50}$, and $\mathrm{Fe}_{75} \mathrm{Ni}_{25}$. For all compositions, the density showed a linear behavior as a function of temperature and can be, respectively, fitted by

$$
\begin{aligned}
& \rho(T)=7.595 \times 10^{3}-0.609\left(T-T_{m}\right)\left(\mathrm{kg} \cdot \mathrm{m}^{-3}\right)\left(1120 \text { to } 1660^{\circ} \mathrm{C}\right)\left(\mathrm{Fe}_{25} \mathrm{Ni}_{75}, T_{m}=1460^{\circ} \mathrm{C}\right), \\
& \rho(T)=7.358 \times 10^{3}-0.590\left(T-T_{m}\right)\left(\mathrm{kg} \cdot \mathrm{m}^{-3}\right)\left(1430 \text { to } 1660^{\circ} \mathrm{C}\right)\left(\mathrm{Fe}_{50} \mathrm{Ni}_{50}, T_{m}=1450^{\circ} \mathrm{C}\right), \\
& \rho(T)=7.205 \times 10^{3}-0.441\left(T-T_{m}\right)\left(\mathrm{kg} \cdot \mathrm{m}^{-3}\right)\left(1260 \text { to } 1600^{\circ} \mathrm{C}\right)\left(\mathrm{Fe}_{75} \mathrm{Ni}_{25}, T_{m}=1475^{\circ} \mathrm{C}\right),
\end{aligned}
$$

where $T_{m}$ is the melting temperature for each binary alloy. In these measurements, the uncertainty was estimated to be less than $2 \%$ from the resolution of the video grabbing capability $(640 \times 480$ pixels $)$ and from the uncertainty in mass measurement $( \pm 0.0001 \mathrm{~g})$. A detailed uncertainty analysis can be found elsewhere [45]. To our knowledge, these measurements are the first to cover such a large temperature span, including the undercooled region. No value for the temperature coefficient was found in the literature for comparison.

The data reported in the open literature were taken for only one temperature. The literature data, whenever necessary, were interpolated to match our compositions and to enable comparison. From Table 1, it can be seen that our data are, within experimental uncertainties $(<2 \%)$, identical to those reported in the literature [25-30]. The merit of the electrostatic levitation is to allow such measurements over a large temperature span.

\section{Summary and Conclusions}

The combination of electrostatic levitation and laser heating is a wonderful approach for the processing, characterization, and study of materials as exemplified in this paper with $\mathrm{Fe}$ $\mathrm{Ni}$ alloys. Furthermore, it shows promise for the synthesis of novel materials by controlling the resulting phases through appropriate cooling.

Property measurements would nonetheless benefit from a few improvements and additions to the current techniques. The density measurement technique is quite mature but a further improvement might allow to resolve the changes in the liquid density due to the structural changes occurring in some liquid phase transitions of glass-forming materials. The use of vacuum ultraviolet or X-ray sources as a background to the sample would offer improved imaging, in particular for samples near $4000 \mathrm{~K}$ and when performing experiments under very high pressure. The surface tension and viscosity data obtained so far are remarkable in a 
sense that they provided measurements unknown before, and that, all the way to tungsten $(>4000 \mathrm{~K})$. However, large scatters still appear in the viscosity data (even when the feedback frequency of the levitation system is diminished [46]) due to the motion of the sample upon exciting the drop oscillation as the feedback control system tends to bring back a perturbed sample to its original position. Moreover, since the electrostatic scheme does not input any heat, a high temperature sample in vacuum experienced pure radiative cooling when the heating sources are shut off. From the simplification of the energy equation governing the cooling, the ratio of constant pressure heat capacity and hemispherical total emissivity could be determined. An independent way to measure the hemispherical total emissivity is currently being pursued [47].

Over the last few years, a strong focus was put on the thermophysical property measurements of refractory materials, in particular elemental metals (e.g., Ta, Os, Re, $\mathrm{W})$. From now on, emphasis will gradually shift towards the property measurements of industrial ceramic and metallic alloys.

Although electrostatic levitation combined with laser heating has shown wide applications and is still in its infancy, some materials are nonetheless difficult to process on the ground. Reduced gravity conditions offered by an orbital platform would allow noncontact positioning of these materials or larger samples while providing an hydrodynamically quiet environment. Similarly, to better understand the effect of gravity on processing, solidification, and vitrification to name but of few, the Japan Aerospace Exploration Agency has pursued, for already several years, the development of an electrostatic levitation facility with laser heating for the International Space Station. The commissioning should occur in the 2013-2014 time frame.

Because electrostatic levitation combined with laser heating offers a variety of processing conditions (large range of pressures $\left(\sim 10^{-5} \mathrm{~Pa}\right.$ to $\left.1 \mathrm{MPa}\right)$ and gaseous compositions (air, $\mathrm{N}_{2}, \mathrm{O}_{2}, \mathrm{Kr}$, etc.), controlled heating (up to $800 \mathrm{~W}$ ), cooling, and solidification), the conditions of outer space or those of planetary atmospheres can be simulated. As such, the technique could be used in processing manmade analogues of the constituents of meteorites, asteroids, transneptunian objects, or comets to better understand body collisions, meteoritic impacts, impact debris, or bolide atmospheric entry.

\section{Acknowledgments}

This work was partially supported by a Grant-in-Aid for Scientific Research (B) from the Japan Society for the Promotion of Science. One of the authors (P. F. Paradis) wishes to acknowledge the Institut national d'optique (Quebec) for short-term sabbatical leaves.

\section{References}

[1] P. F. Clancy, E. G. Lierke, R. Grossbach, and W. M. Heide, "Electrostatic and acoustic instrumentation for material science processing in space," Acta Astronautica, vol. 7, no. 7, pp. 877-891, 1980.
[2] W. K. Rhim, M. Collender, M. T. Hyson, W. T. Simms, and D. D. Elleman, "Development of an electrostatic positioner for space material processing," Review of Scientific Instruments, vol. 56, no. 2, pp. 307-317, 1985.

[3] C. S. Ray and D. E. Day, "Glass formation in microgravity," in Materials Research Society Symposia Proceedings, vol. 87, pp. 239-251, 1987.

[4] G. Sridharan, "A novel sample-positioning system for microgravity application," Review of Scientific Instruments, vol. 61, no. 8, pp. 2251-2253, 1990.

[5] D. M. Herlach, R. F. Cochrane, I. Egry, H. J. Fecht, and A. L. Greer, "Containerless processing in the study of metallic melts and their solidification," International Materials Reviews, vol. 38, no. 6, pp. 273-347, 1993.

[6] F. Babin, J. M. Gagne, P. F. Paradis, J. P. Coutures, and J. C. Rifflet, "High temperature containerless laser processing of dielectric samples in microgravity-study of aerodynamic trapping," Microgravity Science \& Technology, vol. 7, no. 4, pp. 283-289, 1995.

[7] P.-F. Paradis, T. Ishikawa, and S. Yoda, "Development of an electrostatic levitation furnace for the ISS: status of its groundbased thermophysical and structural properties determination capabilities," in Proceedings of the 1st International Symposium on Microgravity Research and Aplications in Physical Sciences and Biotechnology, p. 993, Sorrento, Italy, September, 2001.

[8] T. Ishikawa, P.-F. Paradis, and S. Yoda, "Development of ground-based electrostatic levitation furnace," Journal of the Japan Society of Microgravity Application, vol. 18, no. 2, pp. 106-115, 2001.

[9] T. Ishikawa, P. F. Paradis, and S. Yoda, "New sample levitation initiation and imaging techniques for the processing of refractory metals with an electrostatic levitator furnace," Review of Scientific Instruments, vol. 72, no. 5, pp. 2490-2495, 2001.

[10] P. F. Paradis, T. Ishikawa, and S. Yoda, "Viscosity of liquid undercooled tungsten," Journal of Applied Physics, vol. 97, no. 10, Article ID 106101, 3 pages, 2005.

[11] T. Ishikawa, P. F. Paradis, and S. Yoda, "Noncontact surface tension and viscosity measurements of rhenium in the liquid and undercooled states," Applied Physics Letters, vol. 85, no. 24, pp. 5866-5868, 2004.

[12] S. J. Ostro, D. B. Campbell, J. F. Chandler et al., "Asteroid 1986 DA: radar evidence for a metallic composition," Science, vol. 252, no. 5011, pp. 1399-1404, 1991.

[13] A. S. Rivkin, E. S. Howell, L. A. Lebofsky, B. E. Clark, and D. T. Britt, "The nature of M-class asteroids from 3- $\mu \mathrm{m}$ observations," Icarus, vol. 145, no. 2, pp. 351-368, 2000.

[14] J. F. Bell, D. R. Davis, W. K. Hartmann, and M. J. Gaffey, "Asteroids: the big picture," in Asteroids II, R. P. Binzel, T. Gehrels, and M. S. Matthews, Eds., pp. 921-945, University of Arizona Press, 1989.

[15] E. Anders, "Origin, age, and composition of meteorites," Space Science Reviews, vol. 3, no. 5-6, pp. 583-714, 1964.

[16] S. Sahijpal, P. Soni, and G. Gupta, "Numerical simulations of the differentiation of accreting planetesimals with $26 \mathrm{Al}$ and $60 \mathrm{Fe}$ as the heat sources," Meteoritics \& Planetary Science, vol. 42, no. 9, pp. 1529-1548, 2007.

[17] W. K. Rhim and T. Ishikawa, "Noncontact electrical resistivity measurement technique for molten metals," Review of Scientific Instruments, vol. 69, no. 10, pp. 3628-3633, 1998.

[18] W. K. Rhim, K. Ohsaka, P. F. Paradis, and R. E. Spjut, "Noncontact technique for measuring surface tension and viscosity of molten materials using high temperature electrostatic levitation," Review of Scientific Instruments, vol. 70, no. 6, pp. 2796-2801, 1999. 
[19] W. K. Rhim and P. F. Paradis, "Laser-induced rotation of a levitated sample in vacuum," Review of Scientific Instruments, vol. 70, no. 12, pp. 4652-4655, 1999.

[20] T. Iida and R. I. L. Guthrie, The Physical Properties of Liquid Metals, Clarendon Press, Oxford, UK, 1988.

[21] L. Rayleigh, "On the equilibrium of liquid conducting masses charged with electricity," Philosophical Magazine, vol. 14, pp. 184-186, 1882.

[22] S. Sauerland, G. Lohöfer, and I. Egry, "Surface tension measurements on levitated liquid metal drops," Journal of NonCrystalline Solids, vol. 156-158, no. 2, pp. 833-836, 1993.

[23] J. Q. Feng and K. V. Beard, "Small-amplitude oscillations of electrostatically levitated drops," Proceedings of the Royal Society A, vol. 430, no. 1878, pp. 133-150, 1990.

[24] P. F. Paradis, T. Ishikawa, and S. Yoda, "Electrostatic levitation research and development at JAXA: past and present activities in thermophysics," International Journal of Thermophysics, vol. 26, no. 4, pp. 1031-1049, 2005.

[25] C. Benedicks, N. Ericsson, and G. Ericsson, "Bestimmung des spezifischen volumens von eisen, nickel und eisenlegierungen: im geschmolzenen Zustand," Archiv für das Eisenhuttenwesen, vol. 3, p. 473, 1930.

[26] N. K. Dzhemilev, S. I. Popel, and B. V. Tsarevskii, "Plotnosti i poverkhnostnie svoistva rasplavov jelezo-kobalt-nikel pri 1550 C," Zhurnal Fizicheskoi Khimii, vol. 1, p. 47, 1967.

[27] A. El-Chansan, K. Abdel-Aziz, A. A. Vertman, and A. M. Samarin, "Termokhimia rasplavov na osnove jeleza i nikelia," Doklady Akademii Nauk SSSR, vol. 157, p. 19, 1966.

[28] S. I. Popel, L. M. Shergin, and B. V. Tsarevskii, "Temperature variation of the densities and surface tensions of iron-nickel melts," Russian Journal of Physical Chemistry, vol. 43, p. 1325, 1969.

[29] A. Sharan, T. Nagasaka, and A. W. Cramb, "Densities of liquid Fe-Ni and Fe-Cr alloys," Metallurgical and Materials Transactions B, vol. 25, no. 6, pp. 939-942, 1994.

[30] S. Watanabe, M. Amatatsu, and T. Saito, "Densities of Fe-Ni, Co-Ni, Co-Mo and Co-W alloys in liquid state," Transactions of the Japan Institute of Metals, vol. 12, no. 5, pp. 337-342, 1971.

[31] M. Knudsen, "Die Gesetze der Molekularströmung und der inneren Reibungsströmung der Gase durch Röhren," Annalen der Physik, vol. 28, pp. 75-130, 1909.

[32] P.-F. Paradis, T. Ishikawa, and S. Yoda, "Non-contact measurement technique of the vapor pressure of liquid and high temperature solid materials," The European Physical Journal Applied Physics, vol. 22, no. 2, pp. 97-101, 2003.

[33] P. F. Paradis, T. Ishikawa, and S. Yoda, "Electrostatic levitation furnace for structural studies of high temperature liquid metals by neutron scattering experiments," Journal of NonCrystalline Solids, vol. 312-314, pp. 309-313, 2002.

[34] H. Aoki, P. F. Paradis, T. Ishikawa et al., "Development of an electrostatic levitator for neutron diffraction structure analysis," Review of Scientific Instruments, vol. 74, no. 2, pp. 1147-1149, 2003.

[35] J. T. Okada, T. Ishikawa, Y. Watanabe, P. F. Paradis, Y. Watanabe, and K. Kimura, "Viscosity of liquid boron," Physical Review B, vol. 81, no. 14, Article ID 140201, 2010.

[36] C. Landron, X. Launay, J. C. Rifflet et al., "Development of a levitation cell for synchrotron radiation experiments at very high temperature," Nuclear Instruments and Methods in Physics Research, Section B, vol. 124, no. 4, pp. 627-632, 1997.

[37] S. Ansell, S. Krishnan, J. K. Richard Weber et al., "Structure of liquid aluminum oxide," Physical Review Letters, vol. 78, no. 3, pp. 464-466, 1997.
[38] G. Jacobs and I. Egry, "EXAFS studies on undercooled liquid Co80Pd20 alloy," Physical Review B, vol. 59, no. 6, pp. 39613968, 1999.

[39] T. C. Huang, W. Parrish, N. Masciocchi, and P. W. Wang, "Derivation of $\mathrm{d}$-values from digitized $\mathrm{X}$-ray and synchrotron diffraction data," Advances in X-Ray Analysis, vol. 33, pp. 295303, 1990.

[40] P. F. Paradis, T. Ishikawa, J. Yu, and S. Yoda, "Hybrid electrostatic-aerodynamic levitation furnace for the hightemperature processing of oxide materials on the ground," Review of Scientific Instruments, vol. 72, no. 6, pp. 2811-2815, 2001.

[41] J. K. R. Weber, J. A. Tangeman, T. S. Key et al., "Novel synthesis of calcium oxide-aluminum oxide glasses," Japanese Journal of Applied Physics, vol. 41, no. 5A, pp. 3029-3030, 2002.

[42] J. Yu, P. F. Paradis, T. Ishikawa et al., "Containerless solidification of undercooled $\mathrm{Nd} 2 \mathrm{Fe} 14 \mathrm{~B}$ by electrostatic levitation furnace," Japanese Journal of Applied Physics, vol. 41, no. 5A, pp. 2908-2911, 2002.

[43] J. Yu, P.-F. Paradis, T. Ishikawa, and S. Yoda, "MaxwellWagner effect in hexagonal $\mathrm{BaTIO}_{3}$ single crystals grown by containerless processing," Applied Physics Letters, vol. 85, no. 14, pp. 2899-2901, 2004.

[44] T. Massalski, Ed., Binary Alloy Phase Diagrams, vol. 2, ASM International, 2nd edition, 1996.

[45] T. Ishikawa, P. F. Paradis, R. Fujii, Y. Saita, and S. Yoda, "Thermophysical property measurements of liquid and supercooled iridium by containerless methods," International Journal of Thermophysics, vol. 26, no. 3, pp. 893-904, 2005.

[46] T. Ishikawa, P. F. Paradis, N. Koike, and Y. Watanabe, "Effects of the positioning force of electrostatic levitators on viscosity measurements," Review of Scientific Instruments, vol. 80, no. 1, Article ID 013906, 2009.

[47] Y. Ito, T. Ishikawa, T. Masaki, J. Okada, and P.-F. Paradis, "Not contact spectral emissivity measurement using an electrostatic levitation method," in Proceedings of the 19th European Conference on Thermophysical Properties, Thessaloniki, Greece, August-September 2011. 

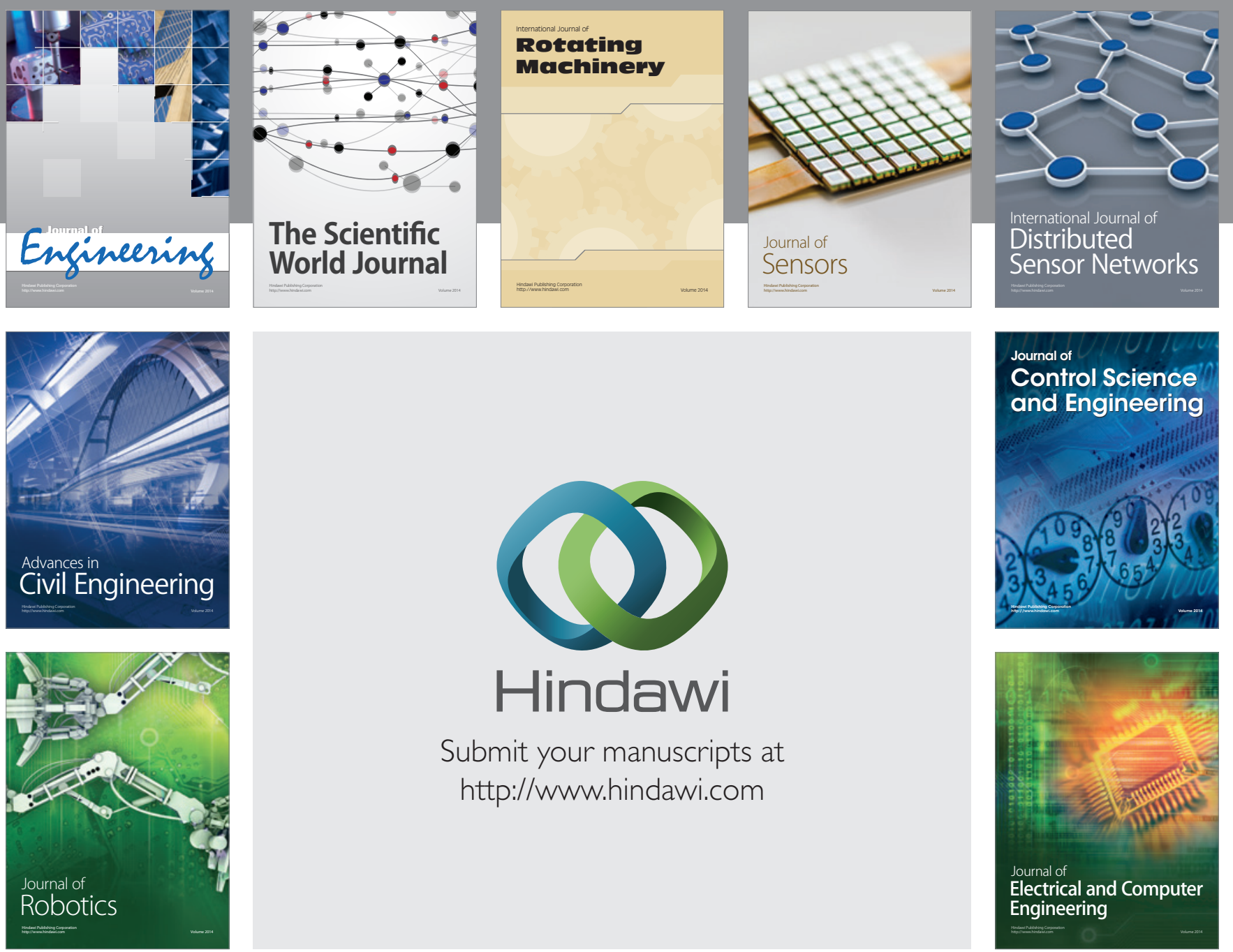

Submit your manuscripts at

http://www.hindawi.com
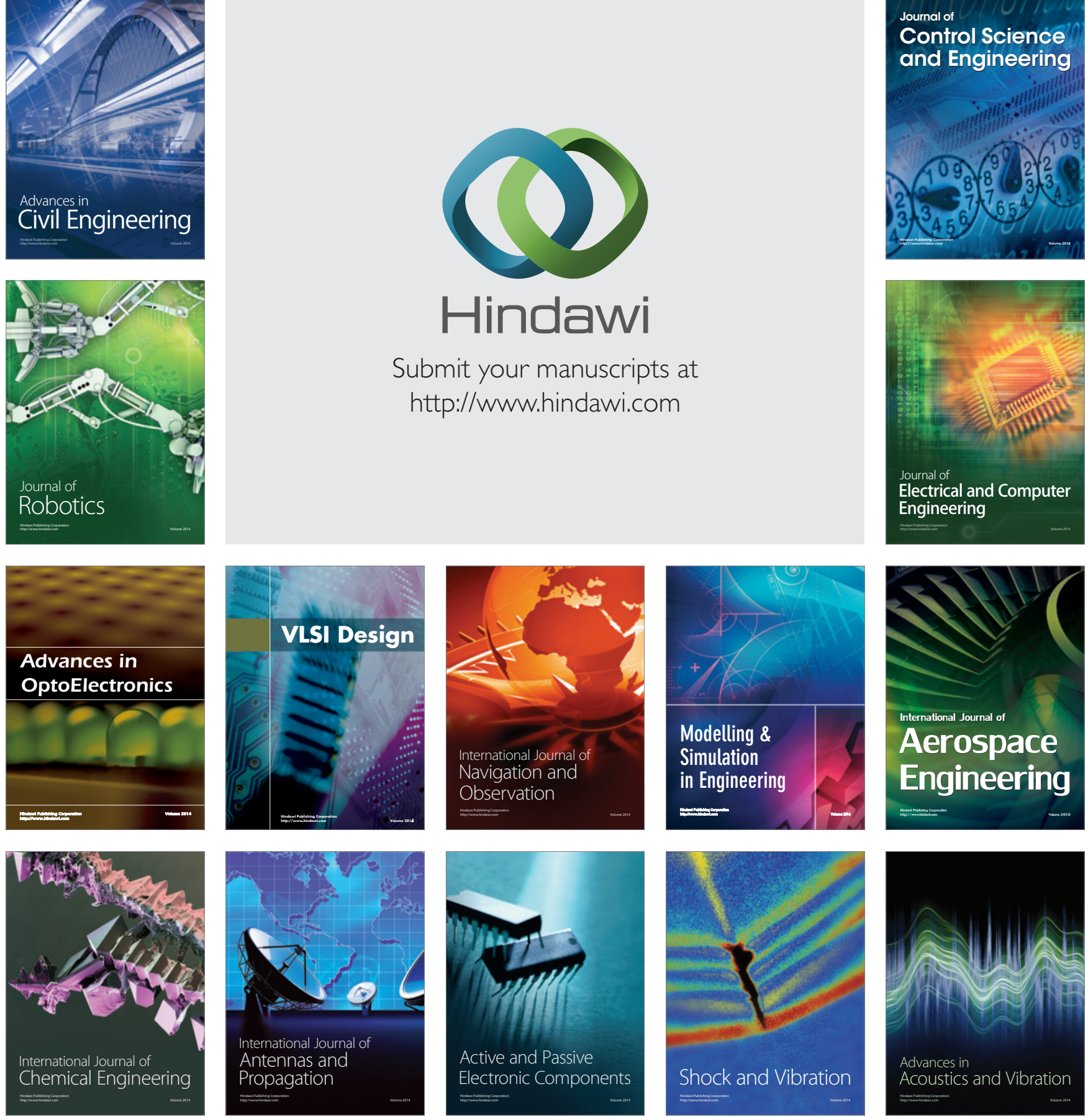